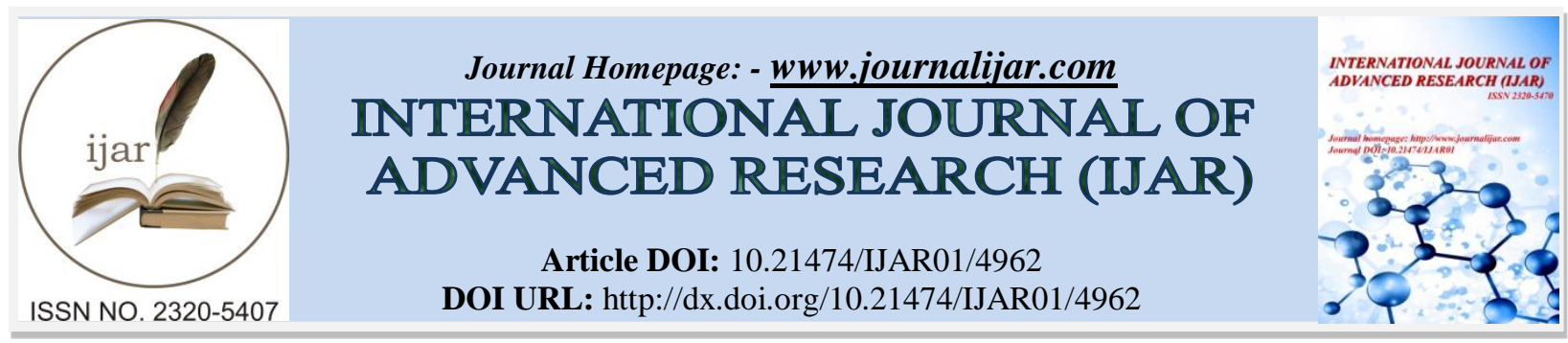

RESEARCH ARTICLE

\title{
GREENHOUSE MONITORING APPLICATIONS: TDMA BASED MAC PROTOCOL FOR ENERGY EFFICIENT WSN.
}

Raju Bhowmik and Ajita Pathak.

Department of Electronics\& Communication Engineering, Amity University, Uttar Pradesh, India.

\section{Manuscript Info}

Manuscript History

Received: 26 May 2017

Final Accepted: 28 June 2017

Published: July 2017

Key words:-

Greenhouse monitoring, wireless sensor network, Scheduling Protocol, AODV, TDMA, QualNet.

\section{Abstract}

Modern greenhouse environment monitoring application require wireless sensor nodes to monitor the parameters like temperature, humidity, soil moisture etc. These sensor nodes are embedded with limited power backup and equipped with limited computing and radio communication capabilities. Therefore it is necessary to reduce the energy consumption of these nodes and requirement of power efficient routing protocols arises. When a proper energy efficient protocol is applied to the wireless sensor network, the power consumption of these nodes can be reduced. In order to fulfill this purpose we have simulated the WSN model using QualNet with the help of AODV routing protocol and Time Division Multiplexing Access (TDMA) based MAC protocol, which is energy efficient as compared to other existing protocols.

Copy Right, IJAR, 2017,. All rights reserved.

\section{Introduction:-}

It is well known that agriculture is backbone of Indian economy and plays a major role in its growth. The $70 \%$ of Indian economy is based on the agriculture. Hence, agriculture is the lifeline of Indian economic and its growth is quite necessary for the development of India and its citizens. Therefore we need to find a good technology that can help in improving the quality of crops and agriculture. A wireless sensor network (WSN) [1] for greenhouse environment parameters control [2] or precision agriculture [3,4] is a powerful technology. A wireless sensor network is made up of tiny sensors which are used for sensing the environment physical data such as atmosphere temperature, humidity, soil moisture, light intensity etc. These sensors digitize the input data and transmit it to the server, which is needed for monitoring and automatic control of the physical data. Wireless sensor network environment is composed of different sensors nodes interconnected with each other, gather environment data and transfer it to sink node. The whole process consumes power. Since the power is provided to these sensors by small battery, which cannot be recharged easily. In this scenario routing protocol plays an important role for communication. Due to limited power source of nodes, an energy efficient routing protocol [5] is required. Nodes should consume less energy for routing mechanism. To reduce the power consumption, the node without any data to transmit or receive may be switched to sleep mode and again to active mode when data is present. Thus, energy efficient schemes for extending the network lifetime should be considered. The purpose of this paper is to analyze the set of performance parameters on TDMA [6] based MAC protocol and AODV [7] routing protocol using QualNet [8] simulation software for better understanding of the protocol efficiency.

Corresponding Author:- Raju Bhowmik.

Address:- Department of Electronics\& Communication Engineering, Amity University, Uttar Pradesh, 


\section{System Model:-}

The wireless sensor node was initiated in the greenhouse that is used to sense and detect the environmental parameters inside greenhouse i.e. atmosphere temperature, relative humidity and carbon dioxide level etc. The sensor node contain with Atmega328 AVR microcontroller [9, 10], DTH11 [11] temperature and humidity sensor, soil moisture sensor and K-30 [12] carbon dioxide sensor.

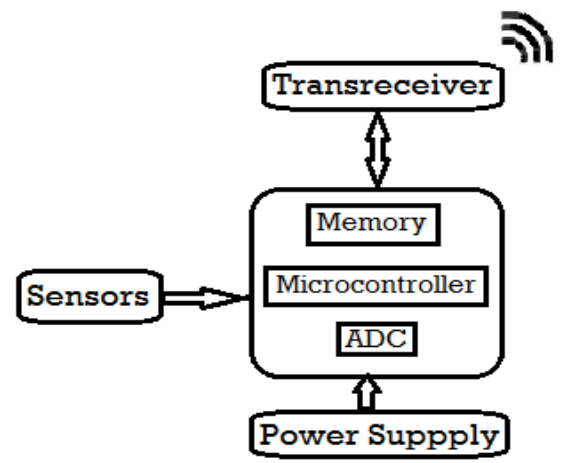

Figure 1:- Block Diagram of Sensor Node

Figure 1 shows the block diagram of a sensor node. DTH11 is a commercially available capacitive type humidity sensor and have a thermistor for temperature sensing. It is available in few packages, generally in $15 \mathrm{~mm} \times 25 \mathrm{~mm}$ plastic box with 4 leads. Its works at $3.5 \mathrm{~V}$ to $5 \mathrm{~V}, 2.5 \mathrm{~mA}$ current and its maximum sampling rate is $1 \mathrm{~Hz}$. It's working temperature range is from 0 to +50 degree Celsius with accuracy of $+/-2$ degree Celsius and humidity range $20-80 \%$ RH with +/- 5.0\% RH humidity accuracy and response time is less than 5 sec.DHT11 has four lines: $\mathrm{GND},+5 \mathrm{~V}, \mathrm{NC}$ and a single data line.

The soil water is an important parameter for the growth of plants, if a minimum amount of water is not present at time of plant growth, the plants quality may go down or even it may not grow. In another side excess amount of water in the soil can prevent to flow the oxygen inside the soil. Therefore a frequency domain soil moisture sensor [13] is used to detect and control the level of water inside the soil. The sensing part of this sensor is inserted in the soil and operating frequency depends on the value of dielectric constant of the soil. Its have fast reaction time, high accuracy.

Carbon dioxide is also an essential parameter for growth of plants. Photosynthesis is a process, through which the plant consume carbon dioxide and it is used to create food. To maintain the level of carbon dioxide inside the greenhouse, we used a non-dispersive infrared type carbon dioxide sensor. The key components of this type of sensors are an infrared source, a mild tube and interference and a detector. It is fast, less power consume, high pollution tolerance and small in length.

\section{Protocols:-}

\section{MAC Protocols:-}

The power supply unit is very small and it should be able to support all the operation without compromise in its performance. As we require the energy efficient communication protocol, we have to select a light weight protocol that consumes less power. A scheduling protocol keeps only minimum number of nodes active at a single time. The TDMA based scheduling protocol [14] makes the node inactive until they have any allocated time slots. The MAC protocols are designed to find out the shortest path for communication and wake up for a particular transmission.

Asynchronous type scheduling protocol is necessary to wake up the nodes in order to send and receive the data. At the same time all the other nodes should be in sleep mode. At the time of switching the condition to be checked is that the energy consumption for switching should be low as compared to the energy consumption when it is in active mode always. This scheduling protocol work in two modes: sleep and active state. The active state is further divided in three states: transmitting, receiving and detecting.

\section{Routing protocols:-}

Adhoc on demand distance vector routing (AODV) is one kind of routing protocol [15] which work on distance vector base mechanism. AODV has two mode of operation, one is discovery and other is maintenance. At initial 
route discovery is initiated when the source node find a new destination or the destination node's life time is expired. Route Request (RREQ), Route Replies (RREP), and the Route Errors (RERRs) are the three message types used by AODC for routing. First initiate by broadcasting the RREQ with the packet which is rebroadcast by the neighbor nodes until the required node is discovered. After receiving the message the destination node uncast an RREP packet itself back to the source node. This is done by receiving the RREQ caches the route back to the source route of RREQ. A flag is set in RREQ for establishing a reverse route between those two routes. If the source node sends a RREP over a link that have an error, the node should set a flag in RREP. So there require an RREP ACK from RREP received route to repeat the message immediate.

\section{Results and Discussion:-}

In continuation to our work [2], we simulated a greenhouse parameter control model as a control application using AODV routing protocol and TDMA based MAC protocol. A WSN simulation model of 5 nodes which is simulate in QualNet is shown in the figure2. The QualNet is a communication simulation platform that is used for planning, testing, and training tool that mimics the behavior and managing network centric system throughout their entire lifecycle. A user can evaluate a basic behavior of network and test combination of network features. The simulation result shows the time and power consumption by these node in different modes. For simulation we select some parameters which are shown below in table 2 .

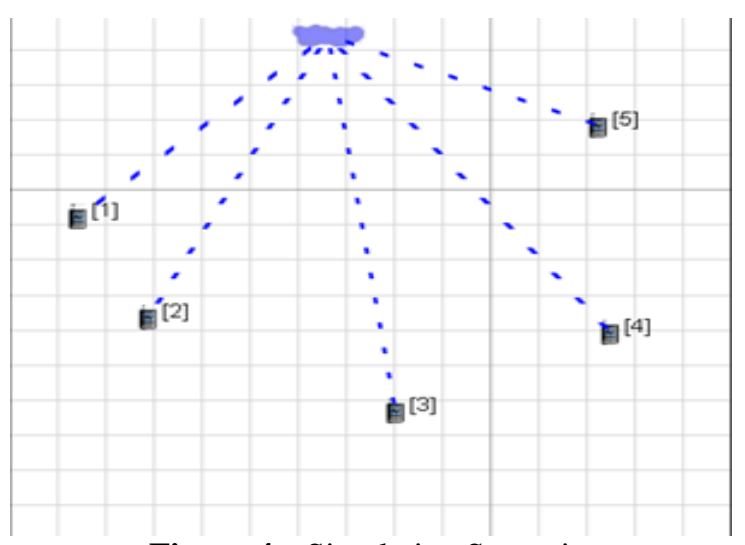

Figure 4:- Simulation Scenario.

Table 2:- Simulation Parameters

\begin{tabular}{|c|c|}
\hline Parameter & Value \\
\hline Channel Type & Channel/wireless channel \\
\hline Radio Type & 802.11 \\
\hline Network interface Type & Wireless \\
\hline MAC Type & TDMA \\
\hline Antenna model & Omni Antenna \\
\hline Number on mobile nodes & AODV \\
\hline Routing Protocol & AOV \\
\hline
\end{tabular}

For AODV routing the performance parameters like time consume, energy consume are simulate in 35 network diameter (hops), node traversal time is 40 milliseconds, active route timeout time is 3 seconds, maximum RREQ retries is 2 and the maximum number of buffered packets is 100. For TDMA based MAC protocol the slot duration set in 10 milliseconds, slot frame is 30 per frame and propagation delay is 1 microseconds. 


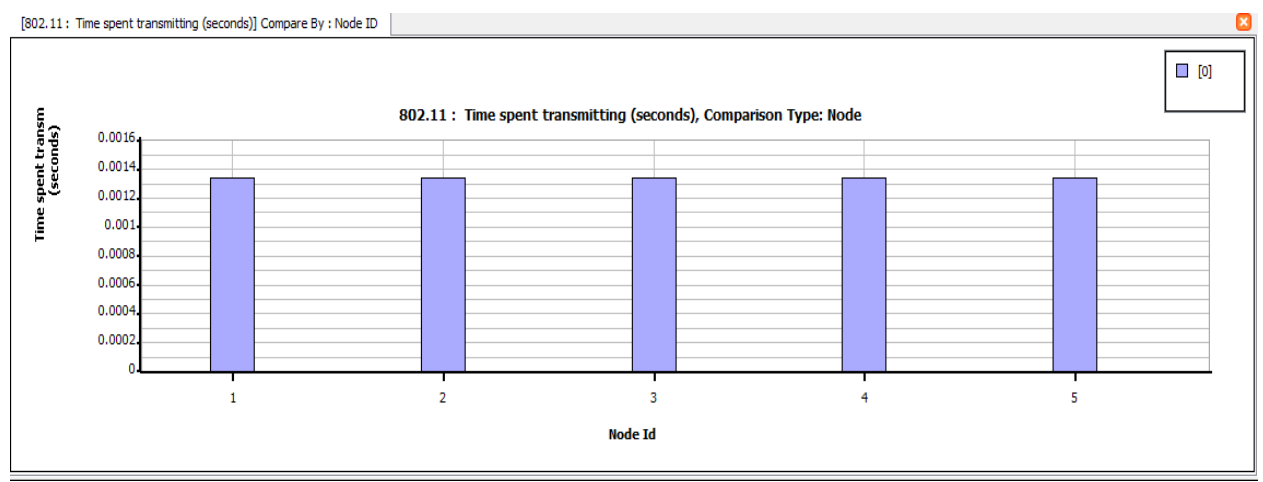

Figure 5:- Time spent in transmit (seconds).

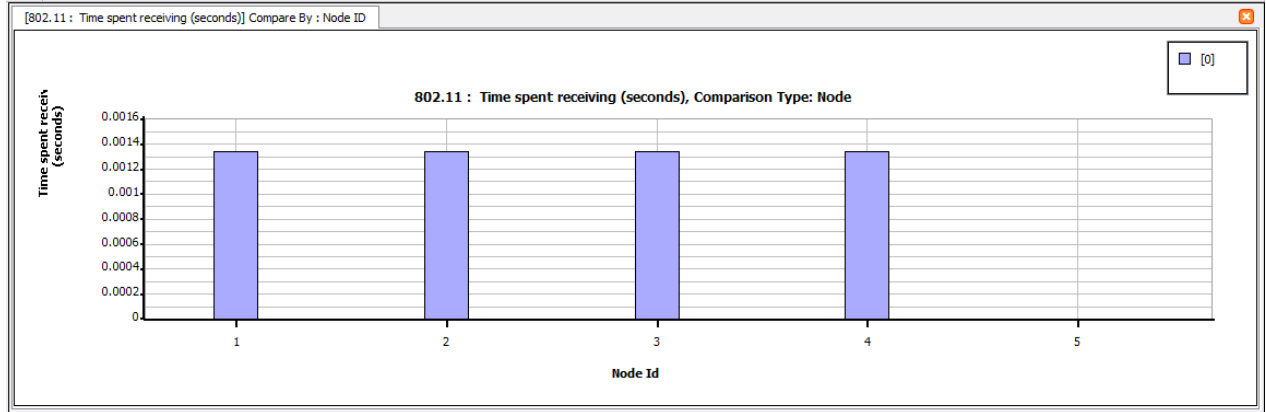

Figure 6:- Time spent (seconds) in receiving modes.

The above described TDMA based scheduling is tested in simulation. For a signal transmission of data packet, the data gathering and then transmitting according to the schedule they require a time to deliver. The above figure 3 and 4 shows the time consumption by the nodes. In the figure 6 we see that the time taken to transmit data packet by a node is 0.001344 seconds and the same time is consumed at the time of receiving of packet except node 5 which shows in the figure 7. From the simulation we can see, there is some transmission delay of node 1 and node 2 due to average path loss, this delay is 1.072 microseconds.

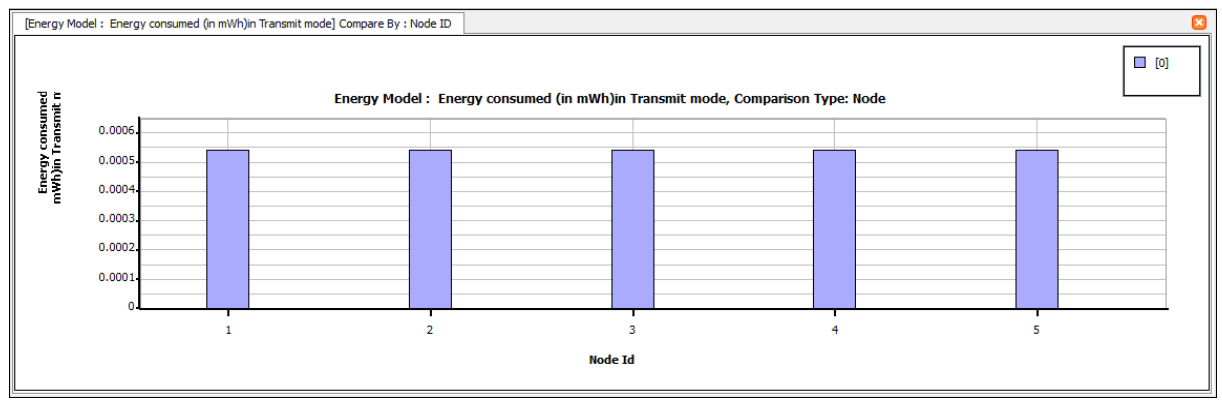

Figure 7:- Energy consumed (mWh) in transmit modes.

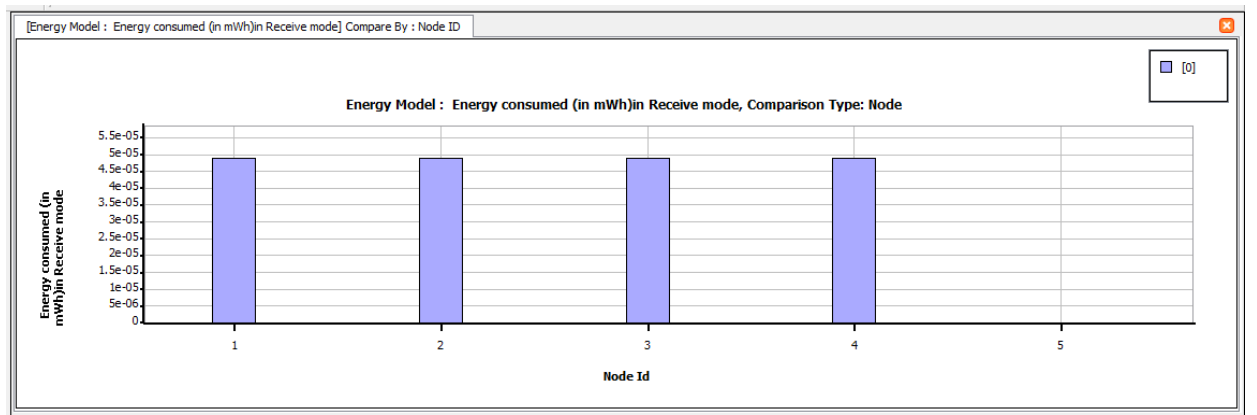

Fig 8:- Energy consumed (mWh) in receive modes. 
Based on the measurement in the simulation, the power consumption of the nodes can be estimated using the modes of operation of the nodes. These nodes work in different modes like transmitting, receiving and sleep. If there is no data to transmit or receive these nodes are goes to sleep modes immediately. From the figure 8 and 9 we can see the power consumption of these nodes at the simulation time. The figure 8 shows the power consumption by the nodes at the time signal or message transmitting and the figure 9 shows the power consumption by the nodes at the time of message receiving. From the figure 8 we see that the power consume by every nodes is 0.000542 mwah at time of message transmitting and the figure 9 shows that 0.000049 mwah power are consumed by these nodes at the time of message receiving except the node 5 . The node 5 only sends the message signal.

We also have simulated the WSN model for two nodes using QualNet with the help AODV routing protocol and time division multiple access based Media Access Control protocol. The simulation of WSN using two nodes is done and it is given in figure 8 and figure 9.

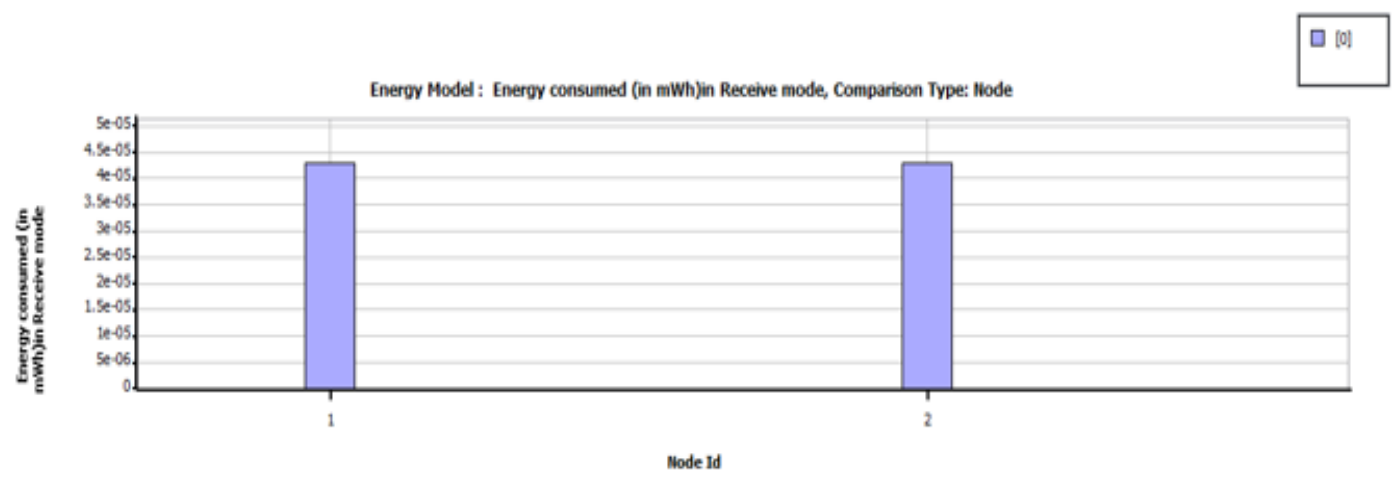

Fig 8:- Energy consumed in receive mode for two nodes (mWh).

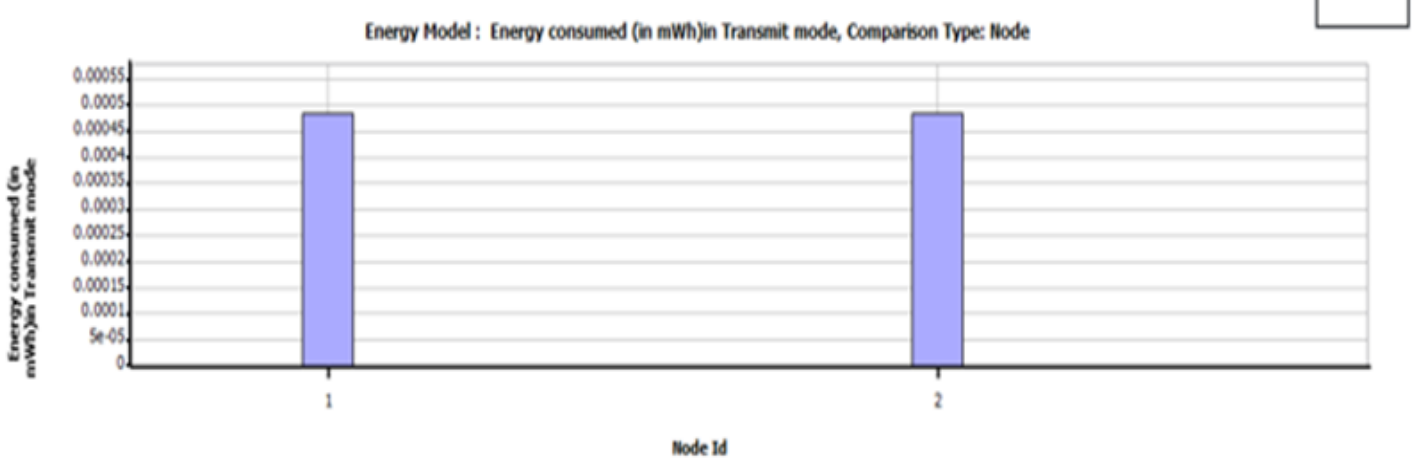

Fig10:- Energy consumed in transmit mode for two nodes ( $\mathrm{mWh}$ )

The figure 7 and figure 8 the energy consumed in transmit mode and energy consumed in the receiving mode is given. Hare we can see that the amount of energy consumed in transmission mode is $0.000485 \mathrm{mWh}$ and the power consumed in receiving mode is $0.000043 \mathrm{mWh}$. With this amount of energy consumption the proposed node is low power node with the transmission of receiving time of 1.2 milliseconds with a delay of .001174 milliseconds. The signal power applied to the node was $-86.766 \mathrm{dBm}$. This shows that the transmitted signal power and received signal power is quiet low.

If we compare the 2 node configuration and 5 node configuration of this WSN on the basis of the energy consumed at the nodes we can see that the energy consumed in five node configuration is more than the energy consumed in two node configuration of the proposed WSN. 
Table 2:- Comparison of WSN in two node and five node configuration

\begin{tabular}{|c|c|c|}
\hline \multicolumn{1}{|c|}{ Parameter } & Two node configuration & Five node configuration \\
\hline Energy consumed in transmit mode & $0.000485 \mathrm{mWh}$ & $0.000542 \mathrm{mWh}$ \\
\hline Energy consumed in receive mode & $0.000043 \mathrm{mWh}$ & $0.000049 \mathrm{mWh}$ \\
\hline Time spent in Transmit\& Receive mode & 1.2 milliseconds & 1.344 milliseconds \\
\hline Delay time & $1.174 \mu \mathrm{sec}$ & $1.072 \mu \mathrm{sec}$ \\
\hline Signal power & $-86.76603 \mathrm{dBm}$ & $-85.18131 \mathrm{dBm}$ \\
\hline Interference & $-120 \mathrm{dBm}$ & $-120 \mathrm{dBm}$ \\
\hline
\end{tabular}

In table 2 we have seen the comparison between two node configuration and five node of the proposed wireless sensor network. In this table we can see that the power consumption in transmit mode in 5 node configuration is 11.75 percent more than the 2 node configuration and power consumption in receive mode is 13.95 percent more than the power consumption in 2 node configuration. We have also observed that the time spent in 5 node configuration is 12 percent more, and time delay is 8.688 percent more than the 2 node configuration but the power consumption is 1.83 percent less than the 2 node configuration of the proposed WSN. With this comparison of both the configuration we can say that 5 node configuration of proposed WSN is less efficient than 2 node configuration in terms of the parameters given in table 2 .

\section{Conclusion:-}

In this paper, we have discussed TDMA based MAC protocol and energy efficient AODV routing protocol for wireless sensor network based on Wi-Fi and analyzed the performance by GUI based simulation. The simulation of this AODV routing protocol shows energy consumption in the wake up and sleep time which helps to reduce the energy consumption. Also we have shown the monitoring results for temperature and humidity variation in summer time varied with the time progress. The day reading of summer season shows that the temperature and humidity curve goes side by side with minimum variation.

\section{Reference:-}

1. Ajita Pathak and VertikaSarkari, "WIRELESS SENSOR NETWORK" Asian Journal of Computer Science and Information Technology 4:7 pp.67 - 71(2014).

2. Raju Bhowmik andAjita Pathak, "AN ARDUINO BASED WSN TO CONTROL AND MONITOR THE GREENHOUSE PARAMETERS" International Journal of Advanced Research (IJAR), ISSN: 2320-5407, vol5(3), pp.1501-1508 (2017).

3. Bakker, J.C., "Greenhouse climate control: an integrated approach", ed. J.C. Bakker. 1995, Wageningen Pers.

4. Yiming Zhou, Xianglong Yang, Liren Wang andYibin Ying, "A wireless design of low-cost irrigation system using ZigBee technology", International Conference on Networks Security, Wireless Communications and Trusted Computing, 978-0-7695-3610-1/09, 2009.

5. ApidetBooranawong, WiklomTeerapabkajorndet and ChusakLimsakul, "Energy Consumption and Control Response Evaluations of AODV Routing in WSANs for Building-Temperature Control", Sensors 2013, 13, 8303-8330; doi: 10, 3390/s130708303. 2013.

6. R. Rathna and A. SivaSubramanian, "TDMA Based Low Energy Consuming MAC Protocol for Wireless Sensor Networks in Environmental Monitoring Applications",Springer-Verlag Berlin Heidelberg, CCIS 203, pp. 420-427(2011).

7. P.Samundiswary and P.Dananjayan, "'Performance Analysis of Trust Based AODV for Wireless Sensor Networks", International Journal of Computer Applications (0975 - 8887) Volume 4- No.12, (August 2010).

8. Nancy Garg, Network Simulators: A Case Study, International Journal of Advanced Research in Computer Science and Software Engineering (ISSN: 2277 1289), Volume 5, Issue 1(January 2015).

9. Steven F. Barrett; Daniel J. Pack, Atmel AVR Microcontroller Primer: Programming and Interfacing, Morgan \& Claypool, ISBN: 9781598295429 first edition, 2007.

10. Nagesh K.D.N. "ARM based remote monitoring and Control System for environmental parameters in greenhouse" (ICECCT), 2015 IEEE International Conference on Electrical, Computer and Communication Technology, pp.1-6, 2015.

11. Meghana. R. Kanitkar, Dr. J. S. Awati, "DESIGNING OF TEMPERATURE \& HUMIDITY MONITORING EMBEDDED SYSTEMS", INTERNATIONAL CONFERENCE ON COMPUTING, COMMUNICATION AND ENERGY SYSTEMS (ICCCES-16), In Association with IET, UK \& Sponsored by TEQIP-II, 29th -30th, Jan. 2016. 
12. Jasmeen Kaur, Viacheslav I. Adamchuk,, Joann K. Whalen and Ashraf A. Ismail, "Development of an NDIR CO2 Sensor-Based System for Assessing Soil Toxicity Using Substrate-Induced Respiration, Sensors" (ISSN 1424-8220) pp.4734-4748; doi:10.3390/s150304734, 2015.

13. Mathew G. Pelletier, Robert C. Schwartz, Greg A. Holt, John D. Wanjura and Timothy R. Green, "Frequency Domain Probe Design for High Frequency Sensing of Soil Moisture" Agriculture, 6(4), 60; doi:10.3390/agriculture6040060. 2016.

14. Hassan Aboubakr Omar and WeihuaZhuang, "VeMAC: A TDMA-Based MAC Protocol for Reliable Broadcast in VANETs", IEEE Transactions on Mobile Computing, Volume: 12, Issue: 9, pp.1724-1736, Sept. 2013.

15. R.Balamurali and K. Kathiravan, "An Analysis of Various Routing Protocols for Precision Agriculture using Wireless Sensor Network”, IEEE International Conference on Technological Innovations in ICT for Agriculture and Rural Development (TIAR 2015). 